\title{
METHOD OF PREDICTING NECKING TRUE STRESS IN A THIN- WALLED TUBE UNDER A COMPLEX STRESS STATE
}

\author{
KOZBUR Halyna \\ Ternopil Ivan Puluj National Technical University, Computer Science Department, Ruska str., 56, \\ Ternopil, Ukraine, e-mail: kozbur.galina@gmail.com
}

\begin{abstract}
Method of predicting the strength of thin-walled tubes under a complex stress state, taking into account changes in the initial dimensions, is proposed. Uniform plastic deformation of a thin-walled tube under short-term static load by internal pressure and axial tension is considered. The tube material is considered to be homogeneous, isotropic and incompressible. The principle of maximum load is used to derive analytical dependences. The main decisions and conclusions were made using the Considere scheme.
\end{abstract}

KEYWORDS: necking, burst pressure, true stress, Considere scheme, thin-walled tube, tangent modulus.

\section{Introduction}

Pipelines made of metal construction materials remain an efficient means of transporting large amounts of water, oil and gas. Today there is a steady trend to increase the values of operating pressure in long-distance pipeline transport systems. If the operation of the pipe system allows the occurrence of plastic deformations, it is critical to be able to accurately predict the loads that initiate the occurrence of local deformations, the emergence of longitudinal macrocracks and accidental destruction. The integrity and safety of pipelines remain important both in terms of operational efficiency and in terms of preventing damage and destruction emergencies.

\section{Problem status}

Numerous studies have been conducted to evaluate the strength of pipes made of isotropic metallic materials, and many analytical expressions have been developed to estimate the burst pressure [1-10]. Law and other researchers [11] conducted a comparative review of the formulas for calculating the burst pressure for thin-walled pipes and concluded that there is no evaluation method that would be accurate at the same time for a wide class of materials. The information with the main existing models for calculation of burst pressure for pipes was generalized in [12].

It should be noted that in real operating conditions, pipelines loaded with internal pressure may also be subjected to axial stresses caused by non-standard factors, such as temperature, mountain conditions, soil mobility, and so on. Therefore, it is important to study the stressstrain state of pipes under conditions of combined loading. As shown in numerous studies [13-22], the effect of axial tension on the bearing capacity of the main pipelines is significant. Based on Mises's criterion, Updike and Kalnins proposed a generalized mathematical model for predicting critical tensile and internal pressure values for axisymmetric thin-walled vessels [23]. However, it was noted that the calculated fracture pressure, which causes the appearance of local plastic deformations, gives inflated values compared to the experimental ones. One of the reasons for the discrepancy between the calculations and the experimental data is, among other things, not taking into account the change in the geometric dimensions of the pipe 
during loading. Therefore, the aim of this study is to obtain analytical dependences for predicting the moment of localization of plastic deformations in the walls of thin-walled pipes under the action of internal pressure and axial tension and at the same time to trace the influence of geometric parameters on strength.

\section{Basic assumptions and relations of the problem}

Consider a thin-walled cylindrical tube with closed ends, loaded statically with axial tension $N$ and internal pressure $q$ (Fig. 1). Let us accept the Kirchhoff-Love hypotheses of the theory of thin-walled shells [24]. Assume that the stress state of a thin-walled cylinder is momentless, the shell material is homogeneous, isotropic, and incompressible.
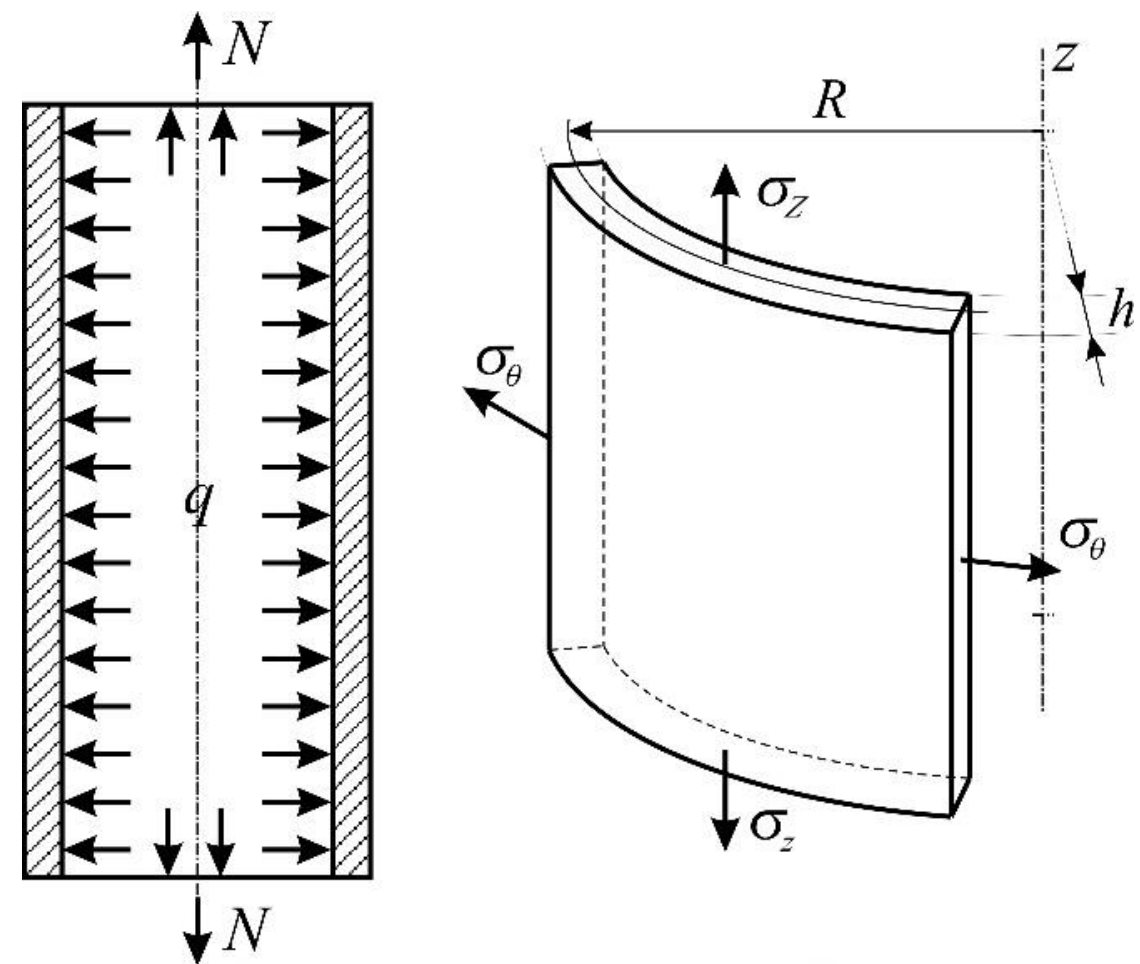

Fig. 1 Scheme of axisymmetric loading of a thin-walled tube by internal pressure and tension

Denote by $l, R$ and $h$ the initial length, radius of the middle surface and wall thickness of the tube, respectively. Axial, hoop and radial stress in the walls of the tube are denoted by $\sigma_{z}$, $\sigma_{\theta}$ and $\sigma_{r}$ respectively. Radial stresses are neglected:

$$
\sigma_{r}=0
$$

Engineering axial stresses arising in the walls of the tube from the action of tensile force $N$, are equal

$$
\sigma_{z}=\frac{N}{2 \pi R h}
$$

Axial $\varepsilon_{z}$, hoop $\varepsilon_{\theta}$ and radial $\varepsilon_{r}$ relative deformations are determined as $\varepsilon_{z}=\frac{\Delta l}{l}$, $\varepsilon_{\theta}=\frac{\Delta R}{R}, \varepsilon_{r}=\frac{\Delta h}{h}$, where $\Delta l, \Delta R, \Delta h-$ absolute changes in the sizes after removal of loading. 
The true axial stresses that develop in the process of plastic deformation are determined by the formula

$$
\left(\sigma_{z}\right)_{\text {true }}=\frac{N}{2 \pi R\left(1+\varepsilon_{\theta}\right) h\left(1+\varepsilon_{r}\right)} .
$$

Consider the case of large uniform plastic deformations. Because in this case the condition of incompressibility of the material has the form

$$
\left(1+\varepsilon_{z}\right)\left(1+\varepsilon_{\theta}\right)\left(1+\varepsilon_{r}\right)=1,
$$

then the formula (3) for finding the true axial stresses arising in the walls of the tube under the action of axial tension will take the form

$$
\left(\sigma_{z}\right)_{\text {true }}=\sigma_{z}\left(1+\varepsilon_{z}\right) \text {. }
$$

Formula (5) coincides with the formula for calculating the values of the actual axial stresses in the stretched rod, obtained by Nadai [25].

Engineering hoop stresses arising from the action of the internal pressure $q$ are found by the formula

$$
\sigma_{\theta}=\frac{q\left(R-\frac{h}{2}\right)}{h}
$$

Taking into account the relative plastic deformations $\varepsilon_{z}, \varepsilon_{\theta}, \varepsilon_{r}$ we obtain the expression for the actual hoop stresses arising from the action of internal pressure:

$$
\left(\sigma_{\theta}\right)_{\text {true }}=\frac{q\left(R\left(1+\varepsilon_{\theta}\right)-\frac{h}{2}\left(1+\varepsilon_{r}\right)\right)}{h\left(1+\varepsilon_{r}\right)} .
$$

Perform identical transformations of expression (7):

$$
\left(\sigma_{\theta}\right)_{\text {true }}=\frac{q\left(R-\frac{h}{2}\right)}{h} \cdot \frac{R\left(1+\varepsilon_{\theta}\right)-\frac{h}{2}\left(1+\varepsilon_{r}\right)}{\left(R-\frac{h}{2}\right)\left(1+\varepsilon_{r}\right)}=\sigma_{\theta}\left(1+\varepsilon_{\theta}\right)\left[\frac{1}{1+\varepsilon_{r}}+\frac{\frac{h}{2} \cdot\left(1-\frac{1+\varepsilon_{r}}{1+\varepsilon_{\theta}}\right)}{\left(R-\frac{h}{2}\right)\left(1+\varepsilon_{r}\right)}\right] \text {. }
$$

Under the action of only the internal pressure, the axial deformations of the tube can be neglected: $\varepsilon_{z} \approx 0$. Then (7) will be reduced to the form:

$$
\left(\sigma_{\theta}\right)_{\text {true }}=\sigma_{\theta} \cdot\left(1+\varepsilon_{\theta}\right)^{2} \cdot\left[1+\frac{\frac{h}{2}}{R-\frac{h}{2}}\left(1-\frac{1}{\left(1+\varepsilon_{\theta}\right)^{2}}\right)\right] .
$$

Because under the action of only the internal pressure, the circular deformations $\varepsilon_{\theta}>0$, then taking into account inequality $0<1-\frac{1}{\left(1+\varepsilon_{\theta}\right)^{2}}<1$ and thinness of the tube $(h<<R)$, the second term in square brackets can be neglected. Taking into account the accepted assumptions, the equation for finding the actual circular stresses in the walls of the tube caused by the action of internal pressure, will take the form:

$$
\left(\sigma_{\theta}\right)_{\text {true }}=\sigma_{\theta} \cdot\left(1+\varepsilon_{\theta}\right)^{2} .
$$

To obtain the condition of loss of plastic deformation stability, we take as a basis the criterion of maximum load: plastic deformations begin to be localized in the neck when the 
pressure or axial load reaches a maximum, analytically expressed by one of two conditions: $d q=0$ та $d N=0[13,26]$.

Let the load be simple, i.e. the stresses vary in proportion to the parameter $k$ :

$$
\frac{\sigma_{z}}{\sigma_{\theta}}=k
$$

Axial and hoop relative deformations will be related by the formula

$$
\varepsilon_{z}=n \varepsilon_{\theta},
$$

that follows from the extension of Hooke's generalized law to the plastic region. The parameters $n$ and $k$ are related by the formula:

$$
n=\frac{2 k-1}{2-k} \text {. }
$$

\section{The condition of loss of strength caused by internal pressure}

A differential equation is obtained from the condition taking into account the incompressibility condition (4) [27]:

$$
\frac{d\left(\sigma_{\theta}\right)_{\text {true }}}{\left(1+\varepsilon_{\theta}\right)^{2}\left(1+n \varepsilon_{\theta}\right)-\frac{h}{2 R}}-\left(\sigma_{\theta}\right)_{\text {true }} \frac{2\left(1+\varepsilon_{\theta}\right)\left(1+n \varepsilon_{\theta}\right)+n\left(1+\varepsilon_{\theta}\right)^{2}}{\left(\left(1+\varepsilon_{\theta}\right)^{2}\left(1+n \varepsilon_{\theta}\right)-\frac{h}{2 R}\right)^{2}} d \varepsilon_{\theta}=0 \text {. }
$$

From (12) we obtain the formula for finding the tangent modulus to the true deformation

curve at a point $\left(\varepsilon_{\theta}{ }^{B},\left(\sigma_{\theta}{ }^{B}\right)_{\text {true }}\right)$, corresponding to the moment of loss of plastic deformation stability, caused by the action of internal pressure $q$ :

$$
\frac{d\left(\sigma_{\theta}\right)_{\text {true }}}{\left(1+\varepsilon_{\theta}\right)^{2}\left(1+n \varepsilon_{\theta}\right)-\frac{h}{2 R}}-\left(\sigma_{\theta}\right)_{\text {true }} \frac{2\left(1+\varepsilon_{\theta}\right)\left(1+n \varepsilon_{\theta}\right)+n\left(1+\varepsilon_{\theta}\right)^{2}}{\left(\left(1+\varepsilon_{\theta}\right)^{2}\left(1+n \varepsilon_{\theta}\right)-\frac{h}{2 R}\right)^{2}} d \varepsilon_{\theta}=0 \text {. }
$$

If $k=0,5$ ( $n=0$ respectively), which corresponds to the load of the tube only by the internal pressure, then formula (13) will be simplified to the form:

$$
\frac{\left(d \sigma_{\theta}\right)_{\text {true }}}{d \varepsilon_{\theta}}=\left(\sigma_{\theta}\right)_{\text {true }} \frac{2}{1+\varepsilon_{\theta}-\frac{h}{2 R}} .
$$

Therefore, when the tube is loaded only by the internal pressure, the subtangent to the deformation curve constructed at true hoop stresses will be a segment $\left(1+\varepsilon_{\theta}-\frac{h}{2 R}\right) / 2$. The value of the subtangent depends on both the level of hoop deformations and the initial geometric parameters of the structure. The growth rate of true hoop stresses in the tube walls caused by internal pressure $q$ depends on the ratio of the thickness of the tube $h$ to its middle radius $R$ (Fig. 2). The smaller the $h / R$ ratio, the slower the true hoop stresses arise and local plastic deformations are formed. 


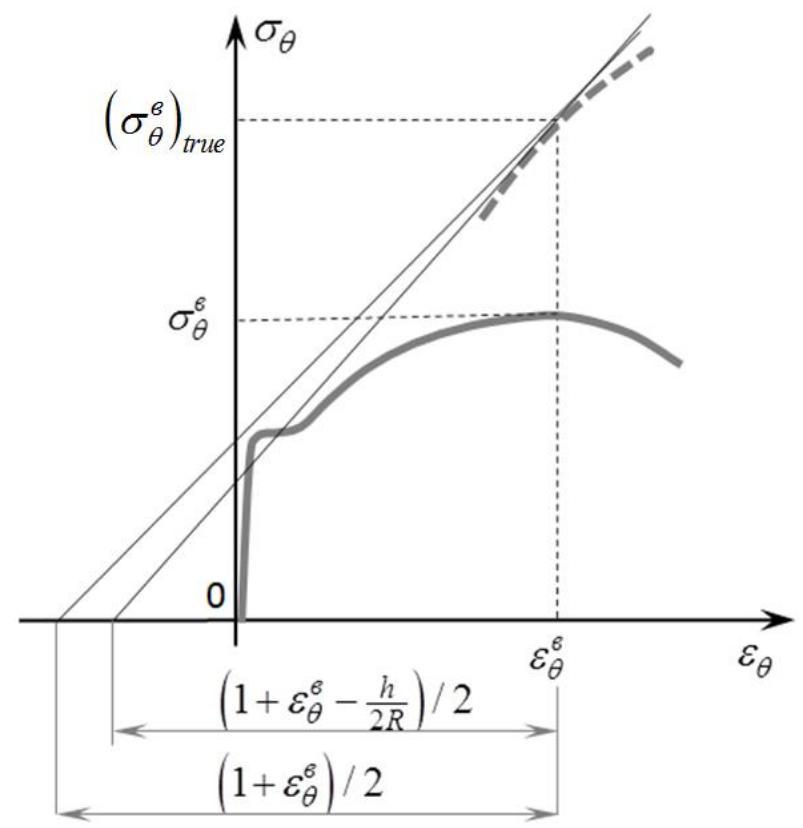

Fig. 2 Geometric interpretation of formula (14) ( - engineering stress-strain curve, - - . - true stress-engineering strain curve)

Neglecting the wall thickness of the tube, from (14) we obtain a formula that establishes the relationship between the limit value of the true hoop dtress and the corresponding value of the tangent module:

$$
\left(\sigma_{\theta}\right)_{\text {true }}=\frac{1}{2} \frac{\left(d \sigma_{\theta}\right)_{\text {true }}}{d \varepsilon_{\theta}}
$$

The multiplier near the tangent module in the right part of the formula for pressure pipes was obtained in the works $[13,26,28]$, and its value ranged from $1 / 2$ to $\sqrt{3} / 3$.

Formula (14) is a specification for relation (15) taking into account the initial geometric parameters of the tube and the level of hoop plastic deformations that develop in the walls of the tube from the load of internal pressure.

\section{The condition of loss of strength caused by axial tension}

Consider the case of the formation of local plastic deformations caused by the action of axial tension, in this case $d N=0$. The thinness of the tube varies slightly compared to the axial deformation, $\frac{h\left(1+\varepsilon_{r}\right)}{R\left(1+\varepsilon_{\theta}\right)} \approx \frac{h}{R}$, as the wall thickness and the radius of the tube decrease simultaneously. As shown in [27], the condition $d N=0$ leads to a differential equation

$$
\frac{d\left(\sigma_{z}\right)_{\text {true }}}{\left(\sigma_{z}\right)_{\text {true }}}=\frac{\left(1-\frac{1}{2 k}+\frac{h}{2 k R}\right) \frac{1}{1+\varepsilon_{z}}+\frac{h}{2 k n R} \frac{1}{1+\frac{1}{n} \varepsilon_{z}}}{1-\frac{1}{2 k}+\frac{h}{4 k R}} d \varepsilon_{z} .
$$

From (16) we obtain the formula for finding the tangent modulus to the true deformation curve at a point $\left(\varepsilon_{z}{ }^{6},\left(\sigma_{z}\right)_{\text {true }}\right)$, corresponding to the moment of loss of plastic deformation process stability caused by action of tensile force $N$ : 


$$
\frac{d\left(\sigma_{z}\right)_{\text {true }}}{d \varepsilon_{z}}=\frac{\left(1-\frac{1}{2 k}+\frac{h}{2 k R}\right) \frac{1}{1+\varepsilon_{z}}+\frac{h}{2 k n R} \frac{1}{1+\frac{1}{n} \varepsilon_{z}}}{1-\frac{1}{2 k}+\frac{h}{4 k R}}\left(\sigma_{z}\right)_{\text {true }} .
$$

The values of the tangent module (17) depend on the type of stress state $k$ and associated with it $n$, as well as the initial geometric parameters of the tube $h$ and $R$.

In the case of loading the tube only with axial tension $(k \rightarrow \infty)$, from (17) we obtain as a partial case the formula

$$
\frac{d\left(\sigma_{z}\right)_{\text {true }}}{d \varepsilon_{z}}=\frac{\left(\sigma_{z}\right)_{\text {true }}}{1+\varepsilon_{z}},
$$

coinciding with the formula for calculating the critical values of the actual axial stresses preceding the formation of the neck in the stretched bar [25]. A similar simplification is obtained regardless of the values of $k$ by putting $h / R \rightarrow 0$. This confirms the possibility of modelling the stress-strain state of a thin-walled tube with a sufficiently small value of $h / R$ due to the tension of the bar. A subtangent to a curve built at true axial stresses, drawn at a point $\left(\varepsilon_{z}{ }^{6},\left(\sigma_{z}^{\beta}\right)_{\text {true }}\right)$, is a segment $1+\varepsilon_{z}^{B}$. A Considere diagram, which is a geometric interpretation of formula (18) to find the true stresses at the necking moment is shown in Fig. 3.

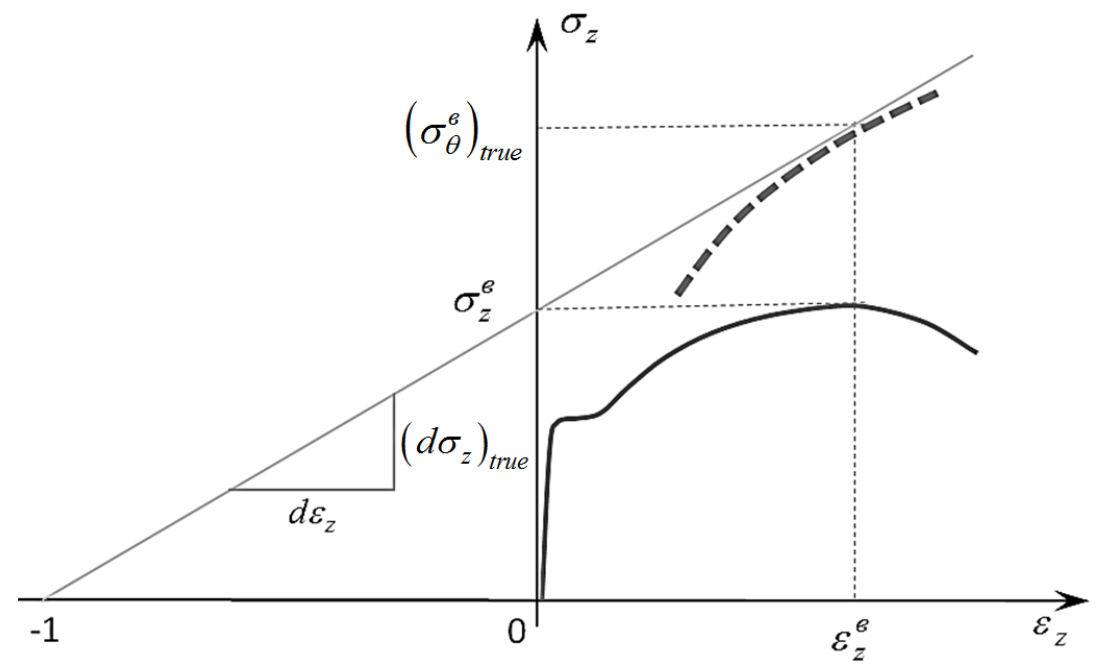

Fig. 3 Considere scheme for finding the ultimate true axial stresses in the tube walls at axial tension ( - engineering stress-strain curve, $-{ }_{-}-$- the strengthening area of true stressengineering strain curve)

\section{Analytical description of the generalized deformation curve in true stresses}

To construct a generalized deformation curve, we use the approach proposed in [29]. Equivalent stresses $\sigma_{e q}$ and equivalent relative deformations $\varepsilon_{e q}$ were introduced in the form:

$$
\sigma_{e q}=\frac{p}{2}\left[\frac{\left|\sigma_{z}-\sigma_{\theta}\right|^{p}+\left|\sigma_{z}-\sigma_{r}\right|^{p}+\left|\sigma_{\theta}-\sigma_{r}\right|^{p}}{2}\right]^{\frac{1}{p}},
$$




$$
\varepsilon_{e q}=\frac{p}{2(p+1)}\left[\frac{\left|\varepsilon_{z}-\varepsilon_{\theta}\right|^{p}+\left|\varepsilon_{\theta}-\varepsilon_{r}\right|^{p}+\left|\varepsilon_{z}-\varepsilon_{r}\right|^{p}}{1 / 2}\right]^{\frac{1}{p}} .
$$

Formulas (19), (20) are generalizations of equivalent coordinates $\tau_{\max }-\gamma_{\max }$ (at $p=1$ ) and $\sigma_{i}-\varepsilon_{i}$ (at $p=2$ ), which are most often used for constructing stress-strain curves. The parameter of the model $p$ can be obtained from the condition of the maximum of the Pearson correlation coefficient for the experimental points in the coordinate system $\sigma_{e q} \square \varepsilon_{e q}$. As shown in [29], for the vast majority of structural materials there is a value $p \in(1 ; 2)$ at which the scattering of experimental points in the coordinate system $\sigma_{e q} \square \varepsilon_{e q}$ is the smallest. Having determined $p$, for the analytical description of the generalized deformation curve in coordinates $\sigma_{e q}-\varepsilon_{e q}$ we can use, for example, a power approximation model:

$$
\sigma_{e q}=A\left(\varepsilon_{e q}\right)^{B}
$$

By analogy with (19) and taking into account that in the process of loading the tube radial stresses remain zero, i.e. $\left(\sigma_{r}\right)_{\text {true }}=0$, we consider the true equivalent stresses that occur in the walls of the tube under a complex stress state in the form:

$$
\left(\sigma_{\text {eq }}\right)_{\text {true }}=\frac{p}{2}\left[\frac{\left|\left(\sigma_{z}\right)_{\text {true }}-\left(\sigma_{\theta}\right)_{\text {true }}\right|^{p}+\left|\left(\sigma_{z}\right)_{\text {true }}\right|^{p}+\left|\left(\sigma_{\theta}\right)_{\text {true }}\right|^{p}}{2}\right]^{\frac{1}{p}} \text {. }
$$

In the case of a simple load from dependences (5) and (8) we obtain:

$$
\left(\sigma_{z}\right)_{\text {true }}=k \frac{1+\varepsilon_{z}}{\left(1+\varepsilon_{\theta}\right)^{2}}\left(\sigma_{\theta}\right)_{\text {true }} .
$$

Then the formula (22) can be written through the true axial stresses:

$$
\left(\sigma_{\text {eq }}\right)_{\text {true }}=\frac{p}{2 k} \frac{\left(\sigma_{z}\right)_{\text {true }}}{1+\varepsilon_{z}}\left[\frac{\left|k\left(1+\varepsilon_{z}\right)-\left(1+\varepsilon_{\theta}\right)^{2}\right|^{p}+\left|k\left(1+\varepsilon_{z}\right)\right|^{p}+\left|\left(1+\varepsilon_{\theta}\right)^{2}\right|^{p}}{2}\right]^{\frac{1}{p}}
$$

or through the true hoop stresses in the form

$$
\left(\sigma_{\text {eq }}\right)_{\text {true }}=\frac{p}{2} \frac{\left(\sigma_{\theta}\right)_{\text {true }}}{\left(1+\varepsilon_{\theta}\right)^{2}}\left[\frac{\left|k\left(1+\varepsilon_{z}\right)-\left(1+\varepsilon_{\theta}\right)^{2}\right|^{p}+\left|k\left(1+\varepsilon_{z}\right)\right|^{p}+\left|\left(1+\varepsilon_{\theta}\right)^{2}\right|^{p}}{2}\right]^{\frac{1}{p}} \text {. }
$$

Taking into account (10) and the condition of incompressibility (4), from (20) we obtain the dependence of equivalent deformations on axial deformations: 


$$
\varepsilon_{e q}=\frac{p \cdot 2^{\frac{1}{p}}}{2(p+1)}\left(\left(\varepsilon_{z}\right)^{p}\left|1-\frac{1}{n}\right|^{p}+\frac{\left|\left(1+\varepsilon_{z}\right)^{2}\left(1+\frac{\varepsilon_{z}}{n}\right)-1\right|^{p}+\left|\left(1+\varepsilon_{z}\right)\left(1+\frac{\varepsilon_{z}}{n}\right)^{2}-1\right|^{p}}{\left(\left(1+\varepsilon_{z}\right)\left|1+\frac{\varepsilon_{z}}{n}\right|\right)^{p}}\right)^{\frac{1}{p}}
$$

In the general case, the family of generalized deformation curves at true stresses for different values can be written as a system:

$$
\left\{\begin{array}{l}
\left(\sigma_{e q}\right)_{\text {true }}=\varphi\left(\sigma_{z}, \varepsilon_{z}, k, p\right), \\
\varepsilon_{e q}=\psi\left(\varepsilon_{z}, k, p\right)
\end{array}\right.
$$

where $\varphi\left(\sigma_{z}, \varepsilon_{z}, k, p\right)$ and $\psi\left(\varepsilon_{z}, k, p\right)$ - dependences described by formulas (24) and (26), respectively, taking into account the relationship between $n$ and $k$ (11). Therefore, the placement of the true generalized deformation curve in equivalent coordinates depends on the parameter $p$ as a material constant and the type of stress state $k$.

Tangent modules to the generalized deformation curve of a thin-walled tube loaded with internal pressure and tension

Taking into account that the true equivalent stresses and equivalent strains are expressed in terms of axial stresses and strains $\sigma_{z}, \varepsilon_{z}$, as shown by the system (27), the expression for finding the tangent modulus is written as:

$$
\frac{d\left(\sigma_{e q}\right)_{\text {true }}}{d \varepsilon_{e q}}=\frac{\frac{d\left(\sigma_{e q}\right)_{\text {true }}}{d \varepsilon_{z}}}{\frac{d \varepsilon_{e q}}{d \varepsilon_{z}}} .
$$

By formula (22) true equivalent stresses are expressed in terms of true axial and true circuit stresses: $\left(\sigma_{e q}\right)_{\text {true }}=f\left(\left(\sigma_{z}\right)_{\text {true }},\left(\sigma_{\theta}\right)_{\text {true }}\right)$.

$$
\frac{d\left(\sigma_{e q}\right)_{\text {true }}}{d \varepsilon_{e q}}=\frac{\frac{d\left(\sigma_{e q}\right)_{\text {true }}}{d \varepsilon_{z}}}{\frac{d \varepsilon_{e q}}{d \varepsilon_{z}}} .
$$

According to the chain rule of finding the derivative of the function we obtain:

$$
\frac{d\left(\sigma_{\text {eq }}\right)_{\text {true }}}{d \varepsilon_{z}}=\frac{\partial\left(\sigma_{\text {eq }}\right)_{\text {true }}}{\partial\left(\sigma_{z}\right)_{\text {true }}} \cdot \frac{d\left(\sigma_{z}\right)_{\text {true }}}{d \varepsilon_{z}}+\frac{\partial\left(\sigma_{\text {eq }}\right)_{\text {true }}}{\partial\left(\sigma_{\theta}\right)_{\text {true }}} \cdot \frac{d\left(\sigma_{\theta}\right)_{\text {true }}}{d \varepsilon_{z}} .
$$

From formula (10) $d \varepsilon_{z}=n d \varepsilon_{\theta}$. Then from (28) we obtain an analytical expression for finding the tangent modulus to the true deformation diagram in equivalent coordinates, which corresponds to the moment of loss of plastic deformation stability of a thin-walled tube loaded with internal pressure and axial tension: 


$$
\frac{d\left(\sigma_{e q}\right)_{\text {true }}}{d \varepsilon_{\text {eq }}}=\frac{\frac{\partial\left(\sigma_{\text {eq }}\right)_{\text {true }}}{\partial\left(\sigma_{z}\right)_{\text {true }}} \cdot \frac{d\left(\sigma_{z}\right)_{\text {true }}}{d \varepsilon_{z}}+\frac{\partial\left(\sigma_{e q}\right)_{\text {true }}}{\partial\left(\sigma_{\theta}\right)_{\text {true }}} \cdot \frac{d\left(\sigma_{\theta}\right)_{\text {true }}}{n d \varepsilon_{\theta}}}{\frac{d \varepsilon_{e q}}{d \varepsilon_{z}}} .
$$

From (24), (25) we obtain derivatives:

$$
\begin{aligned}
& \frac{\partial\left(\sigma_{e q}\right)_{\text {true }}}{\partial\left(\sigma_{z}\right)_{\text {true }}}=\frac{p}{2 k} \frac{1}{1+\varepsilon_{z}}\left[\frac{\left|k\left(1+\varepsilon_{z}\right)-\left(1+\varepsilon_{\theta}\right)^{2}\right|^{p}+\left|k\left(1+\varepsilon_{z}\right)\right|^{p}+\left|\left(1+\varepsilon_{\theta}\right)^{2}\right|^{p}}{2}\right]^{\frac{1}{p}}, \\
& \frac{\partial\left(\sigma_{e q}\right)_{\text {true }}}{\partial\left(\sigma_{\theta}\right)_{\text {true }}}=\frac{p}{2} \frac{1}{\left(1+\varepsilon_{\theta}\right)^{2}}\left[\frac{\left|k\left(1+\varepsilon_{z}\right)-\left(1+\varepsilon_{\theta}\right)^{2}\right|^{p}+\left|k\left(1+\varepsilon_{z}\right)\right|^{p}+\left|\left(1+\varepsilon_{\theta}\right)^{2}\right|^{p}}{2}\right]^{\frac{1}{p}} .
\end{aligned}
$$

Note that taking into account the relationship between true hoop and true axial stresses (23), the partial derivative (32) can be written as $\frac{\partial\left(\sigma_{e q}\right)_{\text {true }}}{\partial\left(\sigma_{\theta}\right)_{\text {true }}}=\frac{k\left(1+\varepsilon_{z}\right)}{\left(1+\varepsilon_{\theta}\right)^{2}} \cdot \frac{\partial\left(\sigma_{e q}\right)_{\text {true }}}{\partial\left(\sigma_{z}\right)_{\text {true }}}$.

Let us to introduce the notation:

$$
\left(\varepsilon_{z}\right)^{p}\left|1-\frac{1}{n}\right|^{p}+\frac{\left|\left(1+\varepsilon_{z}\right)^{2}\left(1+\frac{\varepsilon_{z}}{n}\right)-1\right|^{p}+\left|\left(1+\varepsilon_{z}\right)\left(1+\frac{\varepsilon_{z}}{n}\right)^{2}-1\right|^{p}}{\left(\left(1+\varepsilon_{z}\right)\left|1+\frac{\varepsilon_{z}}{n}\right|\right)^{p}}=A .
$$

Then, using the formula $(|u|)^{\prime}=\frac{u}{|u|} \cdot u^{\prime}$ and denoted $\left(1+\varepsilon_{z}\right)\left(1+\frac{\varepsilon_{z}}{n}\right)=w$ from (26) we obtain:

$$
\begin{gathered}
\frac{d \varepsilon_{e q}}{d \varepsilon_{z}}=\frac{p \cdot 2^{\frac{1}{p}}}{2(p+1)}(A) \frac{1}{p}-1|| 1-\left.\frac{1}{n}\right|^{p}\left(\varepsilon_{z}\right)^{p-1}+\frac{1+\varepsilon_{z}-\frac{1}{w}}{\left|1+\varepsilon_{z}-\frac{1}{w}\right|^{2-p}}\left(1+\frac{1+\frac{1}{n}+2 \frac{\varepsilon_{z}}{n}}{w^{2}}\right)+ \\
+\left[\left|1-\frac{1}{n}\right|^{p}\left(\varepsilon_{z}\right)^{p-1}+\frac{1+\varepsilon_{z}-\frac{1}{w}}{\left|1+\varepsilon_{z}-\frac{1}{w}\right|^{2-p}}\left(1+\frac{1+\frac{1}{n}+2 \frac{\varepsilon_{z}}{n}}{w^{2}}\right)+.\right. \\
\left.+\frac{1+\frac{\varepsilon_{z}}{n}-\frac{1}{w}}{\left|1+\frac{\varepsilon_{z}}{n}-\frac{1}{w}\right|^{2-p}}\left(\frac{1}{n}+\frac{1+\frac{1}{n}+2 \frac{\varepsilon_{z}}{n}}{w^{2}}\right)\right] .
\end{gathered}
$$


Taking into account formula $(|u|)^{2}=u^{2}$ and denoted

$$
\frac{1}{\left(1+\varepsilon_{z}\right)\left(1+\frac{\varepsilon_{z}}{n}\right)}=b,
$$

we can reduce formula (34) to the form

$$
\begin{aligned}
& \frac{d \varepsilon_{e q}}{d \varepsilon_{z}}=\frac{p \cdot 2^{\frac{1}{p}}}{2(p+1)} \cdot(A)^{\frac{1}{p}-1} \times \\
& \times\left(\left(\varepsilon_{z}\right)^{p-1}\left|1-\frac{1}{n}\right|^{p}+\frac{\left|1+\varepsilon_{z}-b\right|^{p}}{1+\varepsilon_{z}-b}\left(1+b^{2}\left(1+\frac{1}{n}+2 \frac{\varepsilon_{z}}{n}\right)\right)+\frac{\left|1+\frac{\varepsilon_{z}}{n}-b\right|^{p}}{1+\frac{\varepsilon_{z}}{n}-b}\left(\frac{1}{n}+b^{2}\left(1+\frac{1}{n}+2 \frac{\varepsilon_{z}}{n}\right)\right) .\right.
\end{aligned}
$$

Substituting in formula (30) the expressions for derivatives (31), (32), (13), (15) and the obtained derivative (36), we obtain a formula for finding the tangent modulus for determining the limit value of true equivalent stresses, in which the process of plastic deformation of the thin-walled tube under the action of internal pressure and tension ceases to be uniform due to the onset of local deformations.

After simplifications, the formula for finding the tangent modulus to the true stress-strain curve in equivalent coordinates will be reduced to the form

$$
\begin{aligned}
& \frac{d\left(\sigma_{\text {eq }}\right)_{\text {true }}}{d \varepsilon_{\text {eq }}}= \frac{p}{2}\left[\frac{\left|k\left(1+\varepsilon_{z}\right)-\left(1+\varepsilon_{\theta}\right)^{2}\right|^{p}+\left|k\left(1+\varepsilon_{z}\right)\right|^{p}+\left|\left(1+\varepsilon_{\theta}\right)^{2}\right|^{p}}{2}\right]^{\frac{1}{p}} \times \\
& \times \frac{\left(\sigma_{z}\right)_{\text {true }}}{k\left(1+\varepsilon_{z}\right)} \frac{\left(1-\frac{1}{2 k}+\frac{h}{2 k R}\right) \frac{1}{1+\varepsilon_{z}}+\frac{h}{2 k n R} \frac{1}{1+\frac{\varepsilon_{z}}{n}}+\frac{\left(\sigma_{\theta}\right)_{\text {true }}}{n\left(1+\varepsilon_{\theta}\right)} \frac{2\left(1+n \varepsilon_{\theta}\right)+n\left(1+\varepsilon_{\theta}\right)}{1+\frac{1}{2 k}+\frac{h}{2 k R}}}{\left(1+\varepsilon_{\theta}\right)^{2}\left(1+n \varepsilon_{\theta}\right)-\frac{h}{2 R}} \\
& \frac{p \cdot 2^{\frac{1}{p}}}{2(p+1)} \cdot(A)^{\frac{1}{p}-1}\left[\left(\varepsilon_{z}\right)^{p-1}\left|1-\frac{1}{n}\right|^{p}+\frac{\left|1+\varepsilon_{z}-b\right|^{p}}{1+\varepsilon_{z}-b}\left(1+b^{2}\left(1+\frac{1}{n}+2 \frac{\varepsilon_{z}}{n}\right)\right)+\frac{\left|1+\frac{\varepsilon_{z}}{n}-b\right|^{p}}{1+\frac{\varepsilon_{z}}{n}-b}\left(\frac{1}{n}+b^{2}\left(1+\frac{1}{n}+2 \frac{\varepsilon_{z}}{n}\right)\right)\right]
\end{aligned} .
$$

Let the slope $\frac{d\left(\sigma_{e q}\right)_{\text {true }}}{d \varepsilon_{e q}}$ of the tangent drawn to the generalized deformation curve in the coordinates $\left(\sigma_{e q}\right)_{\text {true }} \square \varepsilon_{e q}$ acquire the value calculated by formula (37) at some point $\left(\varepsilon_{e q}{ }^{6},\left(\sigma_{e q}{ }^{6}\right)_{\text {true }}\right)$. The position of this point on the curve and the corresponding values of ultimate stresses and strains $\left(\sigma_{e q}{ }^{B}\right)_{\text {true }}, \varepsilon_{e q}{ }^{B}$ depend on the type of stress state $k$, the material constant $p$ and the initial parameters of the tube geometry $h, R$.

As the slope increases, the value of the tangent modulus also increases, the ultimate stresses and strains will decrease, which will lead to a lower threshold of the tube strength. On the contrary, as the value of the tangent modulus decreases, the strength of the thin-walled tube will increase (Fig. 4). 


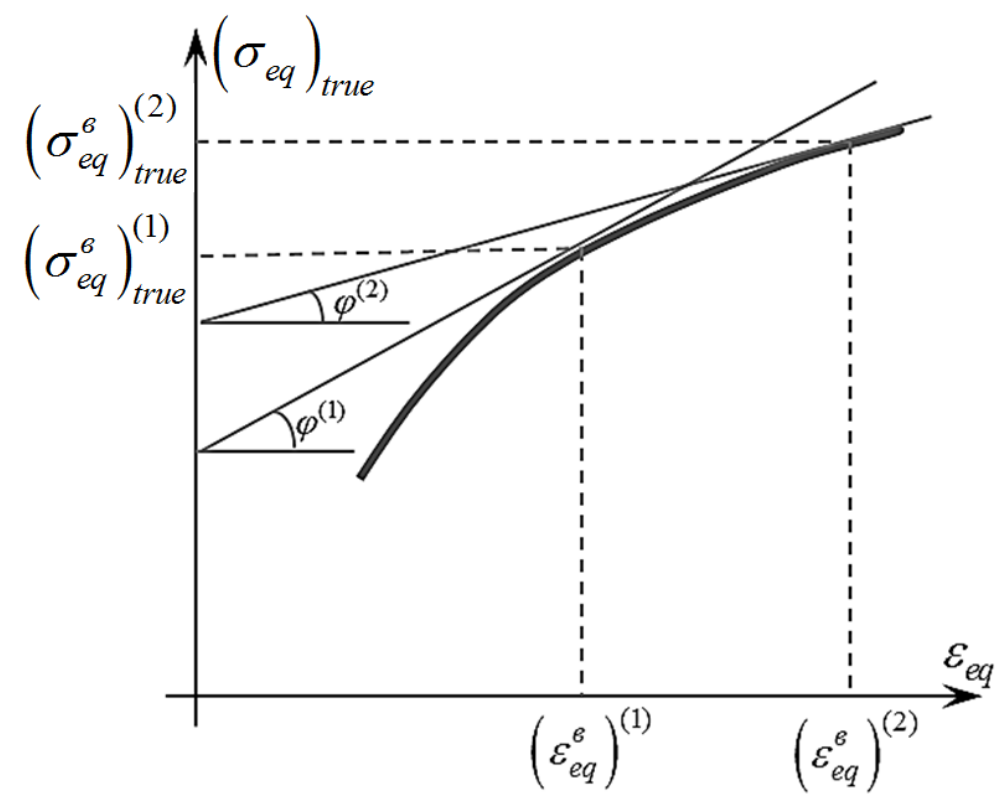

Fig. 4 Influence of the value of the tangent modulus on the values of ultimate stresses and residual deformations

\section{Generalized condition of strength}

The limit values of true stresses $\left(\sigma_{z}\right)_{\text {true }}$ and $\left(\sigma_{\theta}\right)_{\text {true }}$, used in formula (37), are related to the limit values of engineering stresses obtained from axial tension experiments and internal pressure, respectively, by formulas (5) and (8).

Fixing the level of allowable limit uniform axial or circular deformations in the tube walls and finding equivalent deformations, from expression (37) we can determine the corresponding limit levels of true equivalent stresses corresponding to different types of stress $k$ and different parameters of tube geometry $h, R$ (Fig. 5): $\left(\sigma_{e q}^{\beta}\right)_{\text {true }}^{(1)}=g\left(k_{1}, h_{1}, R_{1}\right)$, $\left(\sigma_{\text {eq }}^{B}\right)_{\text {true }}^{(2)}=g\left(k_{2}, h_{2}, R_{2}\right)$.

The greater the level of ultimate true stresses occurs at a given level of axial deformation, the greater the rate of development of local deformations caused by the shape of the tube and the ratio of the applied loads. Conversely, the lower the level of ultimate true stresses develops for a given level of residual axial plasticity, the slower the local deformations will develop, and the greater the service life of the tube with given geometric parameters. 


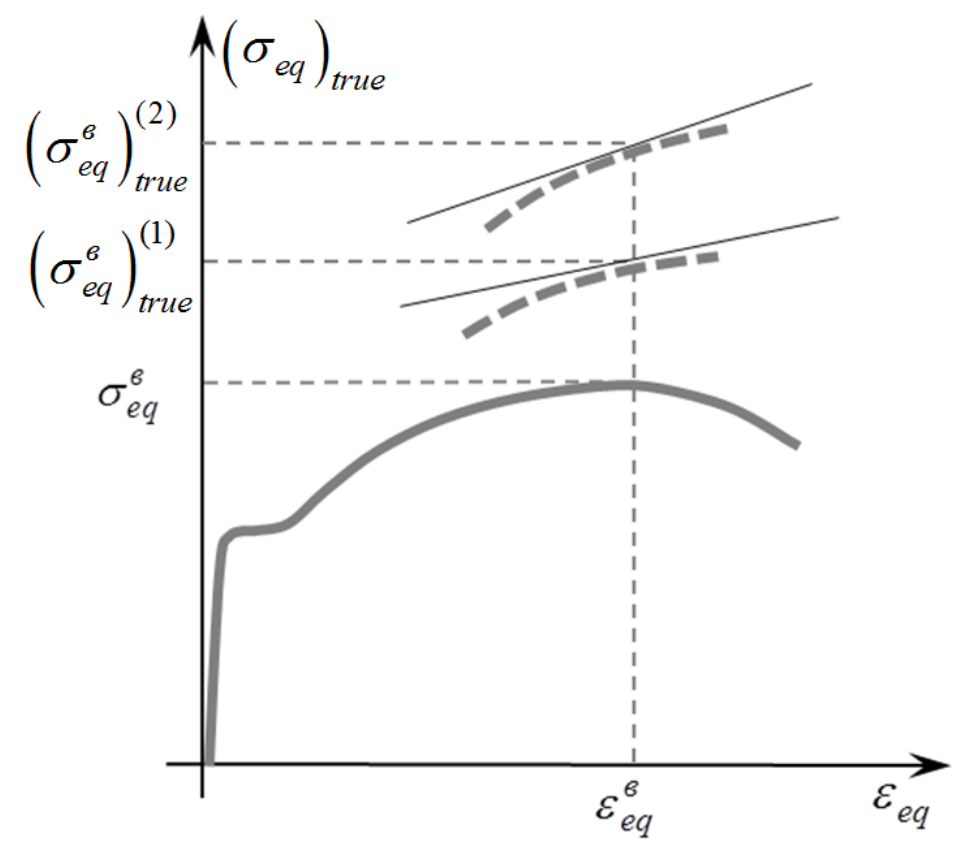

Fig. 5 Finding the ultimate true stresses at different values of $k, h, R$ at a given level of ultimate axial deformations

Taking into account the dependence (24) between true equivalent and true axial stresses, as well as the dependence (25) between true equivalent and true circuit stresses, from (37) we obtain an expression that relates the limits of true equivalent stresses to the value of the tangent modulus to the true stress-strain curve in the system of equivalent coordinates at the necking point:

$$
\begin{aligned}
& \left(\sigma_{e q}\right)_{\text {true }}=\frac{p \cdot 2^{\frac{1}{p}}}{2(p+1)} \cdot(A)^{\frac{1}{p}-1} \times \\
& \times \frac{\left[\left(\varepsilon_{z}\right)^{p-1}\left|1-\frac{1}{n}\right|^{p}+\frac{\left|1+\varepsilon_{z}-b\right|^{p}}{1+\varepsilon_{z}-b}\left(1+b^{2}\left(1+\frac{1+2 \varepsilon_{z}}{n}\right)\right)+\frac{\left|1+\frac{\varepsilon_{z}}{n}-b\right|^{p}}{1+\frac{\varepsilon_{z}}{n}-b}\left(\frac{1}{n}+b^{2}\left(1+\frac{1+2 \varepsilon_{z}}{n}\right)\right)\right]}{\left(1-\frac{1}{2 k}+\frac{h}{2 k R}\right) \frac{1}{1+\varepsilon_{z}}+\frac{h}{2 k n R} \frac{1}{1+\frac{\varepsilon_{z}}{n}}+\frac{2\left(1+\varepsilon_{\theta}\right)\left(1+n \varepsilon_{\theta}\right)+n\left(1+\varepsilon_{\theta}\right)^{2}}{n\left(\left(1+\varepsilon_{\theta}\right)^{2}\left(1+n \varepsilon_{\theta}\right)-\frac{h}{2 R}\right)}} \frac{d\left(\sigma_{e q}\right)_{\text {true }}}{d \varepsilon_{\text {eq }}}
\end{aligned}
$$

The expression near the tangent modulus $\frac{d\left(\sigma_{e q}\right)_{\text {true }}}{d \varepsilon_{e q}}$ in the right part of the formula is a correction factor that takes into account the influence of the stress state and the initial geometric parameters of the tube.

The graph of the left part (38) is a true generalized deformation curve. The right-hand side of equation (38) is the product of the tangent module and the correction factor. The point of intersection of the two graphs will determine the numerical values of the critical equivalent stresses and strains in the walls of the tube, loaded with internal pressure and tension, at the beginning of the localization of plastic deformations (Fig. 6). 


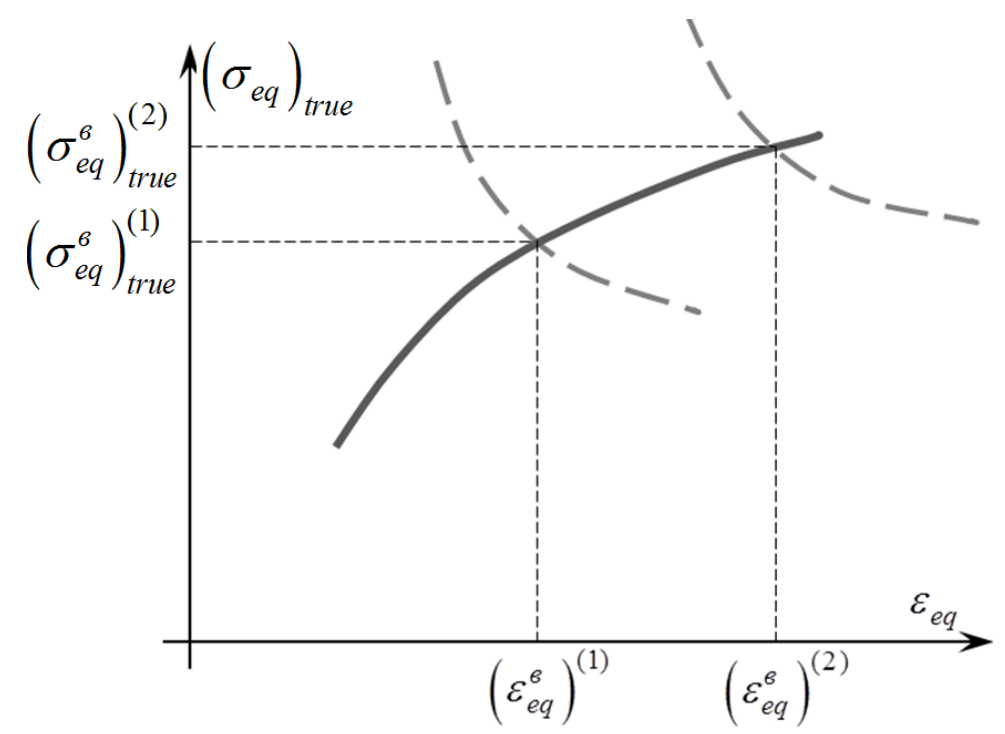

Fig. 6 Graphical interpretation of formula (38). Solid line - generalized strengthening curve, dashed curves - graphs of the right part of formula (38), obtained for different values of $k, h, R$

\section{Algorithm for the method of predicting the strength of a thin-walled tube}

Thus, the general algorithm of the method of predicting the short-term strength of a thinwalled tube, loaded with internal pressure $q$ and axial tension $N$, is formed from a sequence of problems (Fig. 7):

I) finding a constant material $p$;

II) finding the analytical relationship between true stresses and strains in equivalent coordinates and constructing a curve;

III) finding the true limit stresses in equivalent coordinates from equation (38).

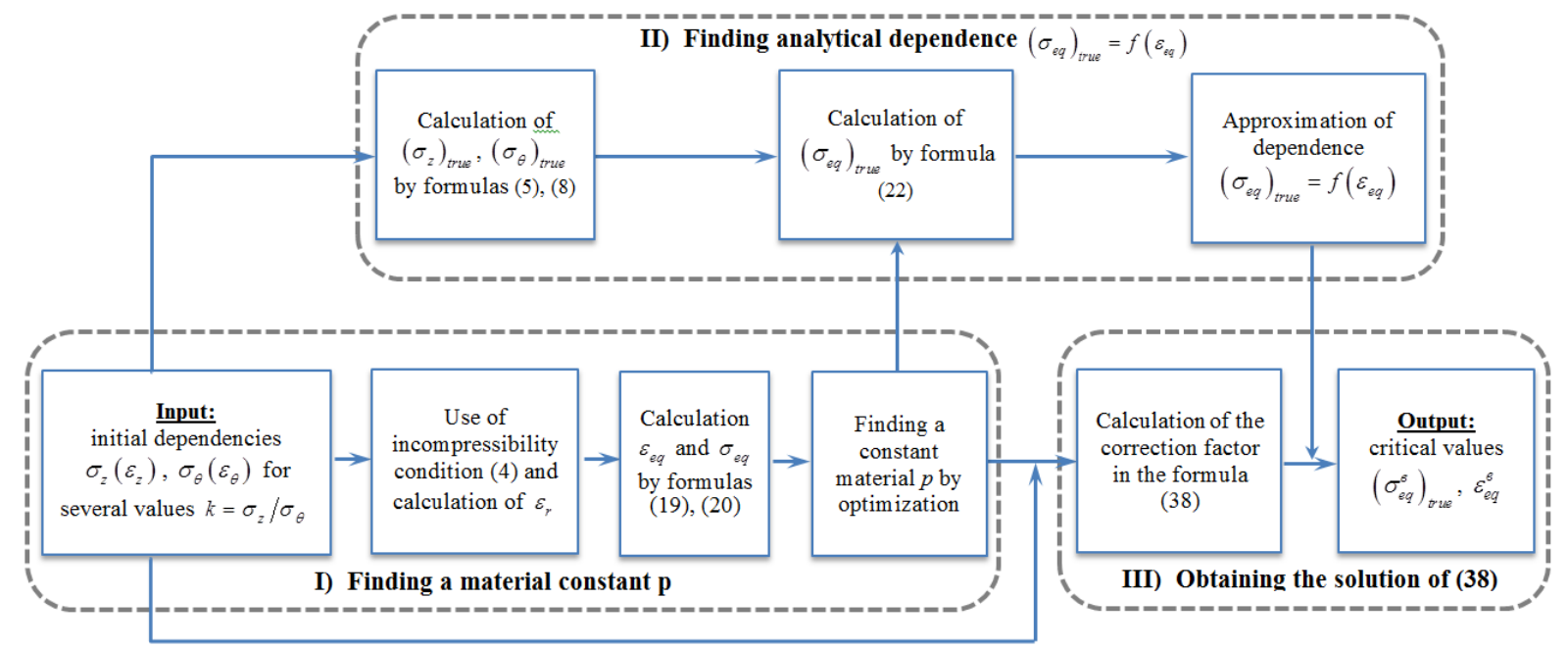

Fig. 7 Algorithm for the method of predicting the short-term strength of a thin-walled cylindrical tube loaded with internal pressure $q$ and axial tension $N$, taking into account changes in tube size

\section{CONCLUSION}

The article develops a generalized method for predicting the short-term strength of thinwalled pipes under a complex stress state using the Considere scheme. The basic formula of 
the method of finding the critical values of true equivalent stresses and strains in the walls of the tube loaded with internal pressure and axial tension, taking into account the type of stress and changes in the geometric dimensions of the tube in the process of uniform plastic deformation. The technique does not take into account other load factors than mechanical forces. An algorithm for implementing the technique is proposed.

Having information as close as possible to the real about the true stress levels in the tube at the necking onset, one can make informed decisions about the choice of safe factor in the design and operation of thin-walled pipes and pressure vessels.

Approbation of the method was carried out for several types of pipes of different geometries, made of different types of isotropic metal materials. The results of the calculations had a satisfactory agreement with the experiment. Since the volume of the methodology and substantiation of analytical decisions covered in this research is quite large, the results of testing the methodology will be presented in additional publications.

Obtaining in partial cases known solutions indicates the adequacy of considerations in the construction of the methodology.

\section{REFERENCES}

[1] Cooper, W. E. "The significance of the tensile test to pressure vessel design", Weld JWeld Res., pp.49 - 56, 1957.

[2] Svensson, N. L. "The bursting pressure of cylindrical and spherical pressure vessels", Trans ASME J. Appl. Mech. 80 (3), pp. 89 - 96, 1958.

[3] Rajan, K. M., Deshpande, P. U. and Narasimhan, K. "Experimental studies on bursting pressure of thin-walled flow formed pressure vessels", J. Mater. Process Technol., pp. 125 - 126, 228 - 234, 2002. DOI: 10.1016/S0924-0136(02)00298-4

[4] Zhu, X. K. and Leis, B. N. "Plastic collapse assessment method for unequal wall transition joints in transmission pipelines”, J. Pres. Ves. Technol. 127 (4), pp. 449 456, 2005. DOI: $10.1115 / 1.2043197$

[5] Zhu, X. K. and Leis, B. N. "Average shear stress yield criterion and its application to plastic collapse analysis of pipelines", Int. J. Pres. Ves. Piping 83(9), pp. 663 - 671, 2006. DOI: 10.1016/j.ijpvp.2006.06.001

[6] Wang, L. Z., Zhang, Y. Q. "Plastic collapse analysis of thin-walled pipes based on unified yield criterion", Int. J. Mech. Sci. 53 (5), pp. 329 - 406, 2011. DOI: 10.1016/j.ijmecsci.2011.02.004

[7] Christopher, T., Rama Sarma, B. S. V., Govindan Potti, P. K., Nageswara Rao, B., Sankarnarayanasamy, K. "A Comparative Study on Failure Pressure Estimations of Unflawed Cylindrical Vessels”, Int. J. Pressure Vessels Piping 79 (1), pp. 53 - 66, 2002. DOI: 10.1016/S0308-0161(01)00126-0

[8] Mihelová, S., Frydrýšek, K., Jančo, R. "Solution of a Gas Pipeline Buried in Ground by Stochastic Approach“, Strojnícky časopis - Journal of Mechanical Engineering 70 (1), pp. 103 - 114, 2020. DOI: $10.2478 /$ scjme-2020-0010

[9] Chmelko, V., Krššák, P. "The elasto-plastic state solution of a heavy-wall cylindrical pressure vessel using bilinear stress-strain model. Part 1: Derivation of analytical relations", Strojnícky časopis - Journal of Mechanical Engineering 64 (1), pp. 51 - 62, 2013. 
[10] Shahabi, M., Esmaeilnejad, M., Ghasemi, A. "A thin-walled tube subjected to combined internal pressure and axial load under different loading paths", Strojnícky časopis Journal of Mechanical Engineering 63 (5-6), pp. 307 - 316, 2012.

[11] Law, M., Bowie, G. and Fletcher, L. "Burst pressure and failure strain in pipeline", Part 2: comparison of burst pressure and failure-strain formulas, J. Pipeline Integrity 3 (2), pp. $102-106,2004$.

[12] Zhu, X.-K., Leis, B. N. "Evaluation of burst pressure prediction models for line pipes", International Journal of Pressure Vessels and Piping, pp. 1 - 13, 2011. DOI: 10.1016/j.ijpvp.2011.09.007

[13] Lankford W. D., Saibel, E. "Some problems in unstable plastic flow under biaxial tension", Metals Technol., pp. 22 - 38, 1947.

[14] Mellor, P. B. "Tensile instability in thin-walled tubes", J. mech. Engng Sci. 4 (3), pp. 251 - 256, 1962. DOI: https://doi.org/10.1243/JMES_JOUR_1962_004_034_02

[15] Monoshkov, A. N. Pykhov, S. I., Pustin, I. A. "Plasticheskaya ustoychivost i eye rol' v otsenke prochnosti trub", Proizvodstvo trub s pokrytiyami, otdelka i kontrol kachestva trub. Metallurgiya. pp. $77-81,1972$.

[16] Kurkin, S. A. "Prochnost svarnykh tonkostennykh sosudov, rabotayushchikh pod davleniyem", 183 p., 1976.

[17] Kovalchuk, B. I. "K voprosu o potere ustoychivosti plasticheskogo deformirovaniya obolochek", Problemy prochnosti. №5. pp. $11-16,1983$.

[18] Kollinz, D. "Povrezhdenie materialov v konstrukciyah. Analiz, predskazanie, predotvrashchenie", 624 p., 1984. Available at: http://books.totalarch.com/n/3598 [Accessed: 20.03.20]

[19] Borodavkin. P. P. "Sooruzheniye magistralnykh truboprovodov" / P.P. Borodavkin, V.L. Berezin. M.: Nedra. 471 p. 1987.

[20] Degtyarev V. P. "Deformatsii i razrusheniye v vysokonapryazhennykh konstruktsiyakh”. M.: Mashinostroyeniye. 105 p., 1987.

[21] "Sistemnaya nadezhnost truboprovodnogo transporta uglevodorodov" / V.D. Chernyayev. K.V. Chernyayev. V.L. Berezin i dr. M.: Nauka. 516 p., 1997.

[22] Dilman. V. L., Ostsemin, A. A. "O vliyanii dvukhosnosti nagruzheniya na nesushchuyu sposobnost trub magistralnykh gazonefteprovodov" Izv. RAN. Mekhanika tverdogo tela. № 5, pp. 179-185, 2000.

[23] Updike, D. P. Kalnins, A. "Tensile plastic instability of axisymmetric pressure vessels", J. Pres. Ves. Technol. 120 (1): pp. 6 - 11, 1998. DOI: 10.1115/1.2841888

[24] Reddy, J. N. "Theory and analysis of elastic plates and shells", CRC Press, Taylor and Francis. 2007. Available at: http://mechanics.tamu.edu/wp-content/uploads/2016/08/11Theory-and-Analysis-of-Elastic-Plates.pdf [Accessed: 23.05.20]

[25] Nadai A. "Plastichnost i razrusheniye tverdykh tel. Tom 1. " Pod red. G.S. Shapiro. v 2kh tomakh. Moskva: Inostrannaya literature, 647 p., 1954.

[26] Jones, B. H., Mellor, P. B. "Plastic flow and instability behaviour of thin-walled cylinders subjected to constant-ratio tensile stress", Journal of Strain Analysis 2 (1), pp. 62 - 72, 1967. DOI: 10.1243/03093247V021062 
[27] Kozbur H. "Prediction technique for thin-walled cylindrical tubes boundary state", Scientific Journal of TNTU (Tern.) 94 (2), pp. 145 - 155, 2019. DOI: 10.33108/visnyk_tntu2019.02.145

[28] Law, M., "Use of the cylindrical instability stress for blunt metal loss defects in linepipe”, International Journal of Pressure Vessels and Piping 82, pp. 925 - 928, 2005. DOI: 10.1016/j.ijpvp.2005.04.002

[29] Kozbur, H., Shkodzinsky, O., Kozbur, I. "Construction of a generalized hardening curve for isotropic plastic metal materials", Scientific Bulletin of I.-Fr. NTU of Oil and Gas 1 (48), pp. 38 - 46, 2020. DOI: 10.31471/1993-9965-2020-1(48)-38-46 